\title{
KOMPOSISI DAN KEPADATAN ZOOPLANKTON DI TELUK AMBON DALAM
}

\author{
Anita Padang ${ }^{1}$, Juferlin Adriaanzs ${ }^{1}$, Madehusen Sangadji ${ }^{*}$ \\ 1Universitas Darussalam Ambon, Email: anita.padang@yahoo.co.id
}

\begin{abstract}
ABSTRAK
Zooplankton merupakan plankton hewani yang penting dalam rantai makanan di perairan. Keberadaan zooplankton mempengaruhi kesuburan perairan tersebut. Teluk Ambon secara geomorfologi terbagi atas dua bagian yaitu Teluk Ambon Dalam (TAD) dan Teluk Ambon Luar (TAL). Pesisir Teluk Ambon saat ini telah menjadi pusat kegiatan perekonomian dan pembangunan. Konsekuensinya muncul berbagai dampak yang secara langsung maupun tidak langsung mempengaruhi kualitas perairan, sehingga tujuan penelitian ini adalah mengetahui komposisi dan kepadatan zooplankton di perairan Teluk Ambon Dalam. Penelitian dilakukan pada bulan Mei-Juni 2012 terdiri atas 7 stasiun (Passo, Latta, Nania, Waiheru, Poka, Halong dan Galala). Pengambilan sampel dilakukan sebanyak 2 kali dengan kedalaman $10 \mathrm{~m}$ setiap stasiun. Identifikasi sampel dilakukan pada Laboratorium Pusat Penelitian Laut Dalam LIPI Ambon. Hasil penelitian ditemukan zooplankton sebanyak 30 jenis holoplakton yang digolongkan dalam 4 phylum yaitu Chaetognatha, Arthropoda, Coelenterata dan Protochordata dan 13 jenis meroplankton yang terdiri dari Molusca, Echinodermata, Annelida dan Larva Ikan. Komposisi zooplankton tertinggi yaitu Arthropoda dengan nilai rata-rata 55\% pada bulan Mei dan $72 \%$ pada bulan Juni. Kepadatan zooplankton tertinggi bulan Mei ditemukan pada stasiun Latta $\left(31.878 \mathrm{ind} / \mathrm{m}^{3}\right)$ dan terendah pada stasiun Halong (20.196 ind/ $\left.\mathrm{m}^{3}\right)$, dan bulan Juni kepadatan tertinggi pada stasiun Latta (33.516 ind/ $\left./ \mathrm{m}^{3}\right)$ dan terendah pada stasiun Halong (14.364 ind $\left./ \mathrm{m}^{3}\right)$.
\end{abstract}

Kata Kunci : Zooplankton, Teluk Ambon Dalam, Komposisi dan Kepadatan

\section{PENDAHULUAN}

Teluk Ambon merupakan bagian penting dari Pulau Ambon yang secara geomorfologi terbagi atas dua bagian yaitu: 1) Teluk Ambon Dalam yang berbentuk hampir bulat dengan kedalaman maksimum 30-40 meter dan kedalaman rata-rata 25 meter serta bersifat semi tertutup ; 2) Teluk Ambon Luar berbentuk kerucut dan bersifat lebih terbuka. Kedua teluk ini dipisahkan ambang Galala-Rumahtiga dengan kedalaman antara 9-13 meter (Nontji, 1996).

Pesisir Teluk Ambon saat ini telah menjadi pusat kegiatan perekonomian dan pembangunan.Teluk Ambon Dalam dikenal sebagai ladang ikan umpan, perikanan perikanan tangkap dan perikanan budidaya (Salili $d k k$, 2007). Perairan Teluk Ambon Dalam juga digunakan sebagai tempat pembuangan limbah rumah tangga dari pemukiman penduduk yang terletak disepanjang pesisir. Konseksuensinya muncul berbagai dampak yang secara langsung maupun tidak langsung mempangaruhi kualitas perairan di Teluk dan selanjutnya akan mempengaruhi kehidupan organisme di dalamnya.

Organisme di perairan sangat beragam dan dapat diklasifikasikan berdasarkan bentuk kehidupannya atau kebiasaan hidupnya yaitu: bentos, periphyton, plankton, nekton dan neuston. Plankton adalah organisme melayang atau mengambang di dalam air, kemampuan geraknya kalaupun ada, sangat terbatas sehingga organisme tersebut selalu terbawa oleh arus (Kaswadji, 2001). 
Plankton dapat dibagi menjadi 2 golongan yaitu fitoplankton yang disebut plankton nabati dan zooplankton yang disebut plankton hewani. Zooplankton merupakan plankton hewan yang banyak terdapat di massa air (Nontji, 1987).

Menurut Nybakken (1988) dalam Fachrul (2006) bahwa zooplankton sangat beraneka ragam, terdiri atas berbagai bentuk larva dan bentuk dewasa yang dimiliki hampir seluruh filum hewan serta zooplankton menempati posisi penting dalam rantai makanan dan jaring-jaring kehidupan di perairan, dimana zooplankton merupakan penghubung tingkatan trofik terendah (fitoplankton) ke tingkatan trofik tertinggi (sumberdaya ikan) dalam rantai makanan di laut serta berfungsi sebagai pembawa energi ke laut dalam, karena zooplankton dapat berenang 500 meter ke atas dan bawah (migrasi vertikal) dalam sehari, juga berperan sebagai bioindikator perubahan kondisi lingkungan (Kaswadji, 2001).

Keanekaragaman zooplankton yang tinggi menyebabkan rantai makanan di suatu perairan semakin kompleks. Dilihat dari perannya sebagai mediator transfer energi, maka kekayaan dan kelimpahan zooplankton akan menentukan kesuburan suatu perairan seperti melimpahnya berbagai ikan kecil disusul ikan besar sehingga akhirnya membentuk suatu daerah penangkapan (fishing ground).

Mengetahui keadaan zooplankton di suatu perairan dapat diprediksikan tentang kesuburan perairan tersebut. Dengan demikian tujuan penelitian ini adalah untuk mengetahui komposisi dan kepadatan zooplankton di perairan Teluk Ambon Dalam.

\section{METODOLOGI PENELITIAN}

\subsection{Waktu dan Lokasi Penelitian}

Penelitian dilakukan di perairan Teluk Ambon Dalam pada bulan Mei - Juni 2012.

Lokasi penelitian pada Teluk Ambon Dalam terdiri dari 7 stasiun dengan karakteristik : Stasiun 1 (Passo) merupakan daerah berlumpur yang ditumbuhi oleh vegetasi ekosistem mangrove, Stasiun 2 (Latta) dan stasiun 3 (Nania) dipengaruhi oleh aktivitas masyarakat berupa pembuangan limbah rumah tangga, stasiun 4 (Waiheru) aktivitas pembudidaya keramba jaring apung, vegetasi mangrove dan adanya aliran air sungai, stasiun 5 (Poka) dipengaruhi oleh akitivitas PLTD berupa pembuangan limbah, stasiun 6 (Halong, berdekatan dengan pelabuhan) pembuangan limbah rumah tangga dan pembuangan bilasan air kapal serta penumpahan minyak, pada stasiun terakhir yaitu stasiun 7 (Galala) aktivitas lalu lintas penyebrangan fery.

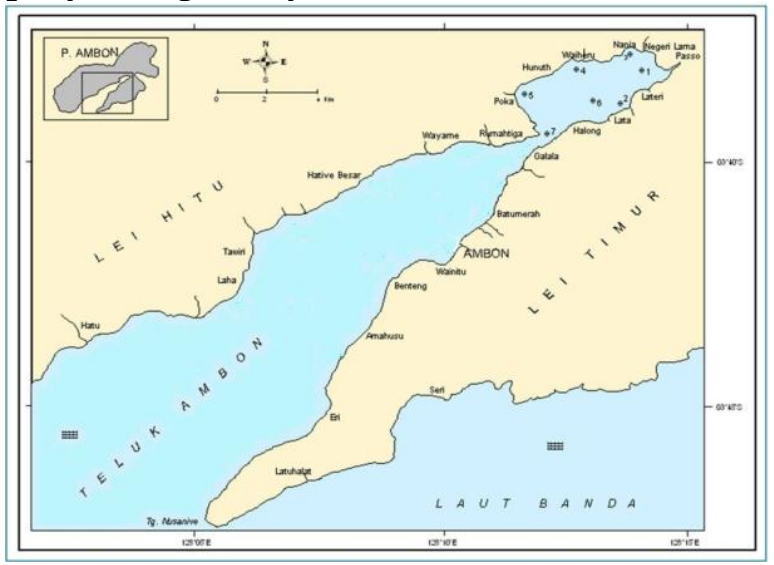

Gambar 1. Peta Lokasi Penelitian (Sumber : LIPI, 2012)

\subsection{Prosedur Penelitian}

a. Metode Sampling

Pengambilan sampel dilakukan sebanyak dua kali yaitu pada bulan Mei dan Juni. Pengambilan sampel dilakukan secara vertikal pada kedalaman $10 \mathrm{~m}$. Sampel dimasukkan kedalam botol yang telah berisi formalin $4 \%$ dan selanjutnya diindentifikasi di Laboratorium Ekologi Pusat Penelitian Laut Dalam LIPI Ambon.

b. Metode Analisa Laboratorium

Sampel zooplankton selanjutnya diendapkan dan diencerkan terlebih dahulu, kemudian diambil sampel sebanyak $5 \mathrm{ml}$ menggunakan pipet stempel dan dimasukan dalam cawan bogorov untuk diamati di bawah mikroskop Nikon SMZ645 dan Nikon Eclipse 50i dengan pembesaran 100X. Pengamatan sampel dilakukan sebanyak 3 kali pengulangan Indetifikasi sampel merujuk pada buku identifikasi Yamaji (1966).

c. Metode Analisa Data

1. Komposisi zooplankton dihitung mengunakan formula yang dikemukakan oleh Fachrul, (2006):

$\mathrm{Kj}=\mathrm{ni} / \mathrm{N} \times 100 \%$

Dimana:

$\mathrm{Kj}=$ Komposisi jenis zooplankton 


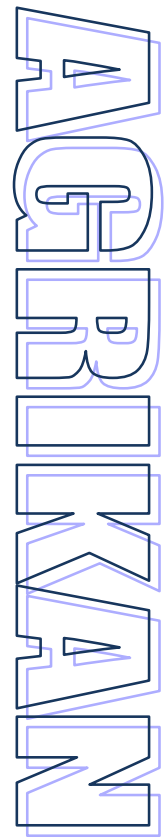

ni $=$ Jumlah individu setiap jenis zooplankton

$\mathbf{N}=$ Jumlah individu seluruh jenis zooplankton

2. Kepadatan zooplankton dihitung dengan formula, (Arinardi, 1976):

$\mathrm{K}=\mathbf{n} \times 1 / \mathrm{f} \times 1 / \mathrm{v}$

Dimana:

$\mathrm{K}=$ Nilai kepadatan zooplankton (ind $/ \mathrm{m}^{3}$ )

$\mathbf{n}=$ Jumlah individu setiap jenis zooplankton hasil pencacahan (ind ; sel)

$\mathrm{f}=$ Fraksi yang dipergunakan atau diambil

$\mathbf{v}=$ Volume air tersaring $\left(\mathrm{m}^{3}\right)$

3. Volume air tersaring diperoleh dari formula:

$\mathrm{V}=\pi \mathbf{r}^{2} \mathbf{s}$

Dimana:

$\mathrm{V}=$ Volume air tersaring $\left(\mathrm{m}^{3}\right)$

$r=$ Jari-jari bagian depan mulut jaring

$\mathrm{s}=$ Jarak yang di tempuh oleh jaring (m)

$\pi=$ Konstanta $(3,14)$

\section{HASIL DAN PEMBAHASAN}

\subsection{Komposisi Zooplankton}

Hasil penelitian pada ketujuh stasiun penelitian ditemukan jumlah holoplankton sebanyak 30 jenis dan meroplakton sebanyak 13 jenis yang terdistribusi berbeda pada kedua bulan penelitian yaitu bulan Mei sebanyak 27 jenis holoplankton dan meroplankton 10 jenis sedangkan bulan Juni ditemukan holoplankton sebanyak 29 jenis dan meroplankton 11 jenis, seperti terlihat pada gambar di bawah ini.

Ternyata kehadiran jenis pada kedua bulan didominasi oleh holoplankton, seperti yang ditemukan Mulyadi dan Radjab (2015) di perairan pesisir Morella Maluku Tengah dan Karuwal (2015) di Teluk Ambon Dalam. Tingginya komposisi holoplankton di suatu perairan mengindikasikan besarnya potensi makanan alami bagi meroplankton (larva biota laut tertentu) ketika cadangan kuning telur sudah habis dan mengharuskan mencari sumber asupan makanan dari luar, sehingga dengan semakin beragamnya komposisi holoplankton di suatu perairan dapat mendukung ketersediaan makanan bagi meroplankton (Mulyadi dan Radjab, 2015).

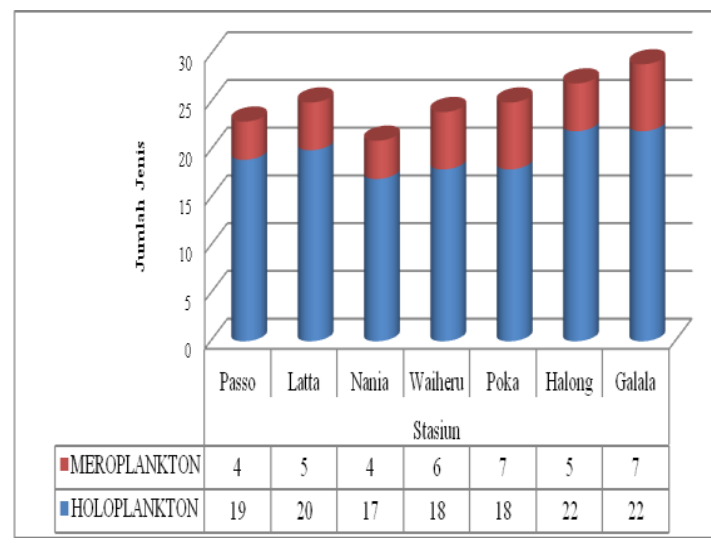

Gambar 2. Zooplankton Bulan Mei (Sumber : Data Primer 2012)

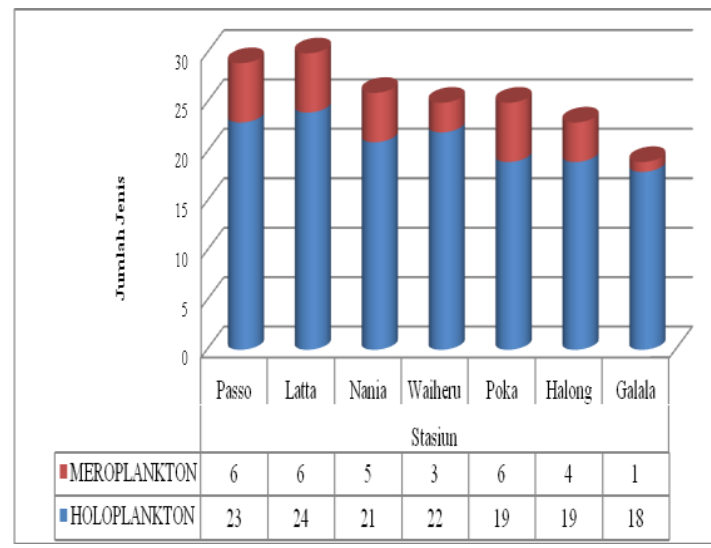

Gambar 3. Zooplankton Bulan Juni (Sumber : Data Primer 2012)

Holoplankton yang ditemukan terdiri dari 4 phylum yaitu Chaetognatha, Arthropoda, Coelenterata dan Protochordata sedangkan meroplakton terdiri dari Molusca, Echinodermata, Annelida dan Larva Ikan.

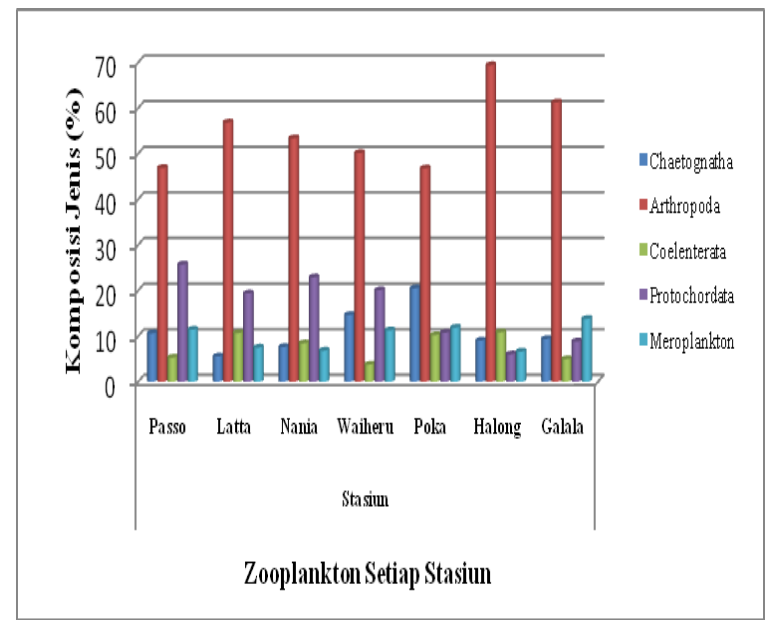

Gambar 4. Komposisi Jenis Zooplankton Bulan Mei (Sumber : Data Primer 2012) 


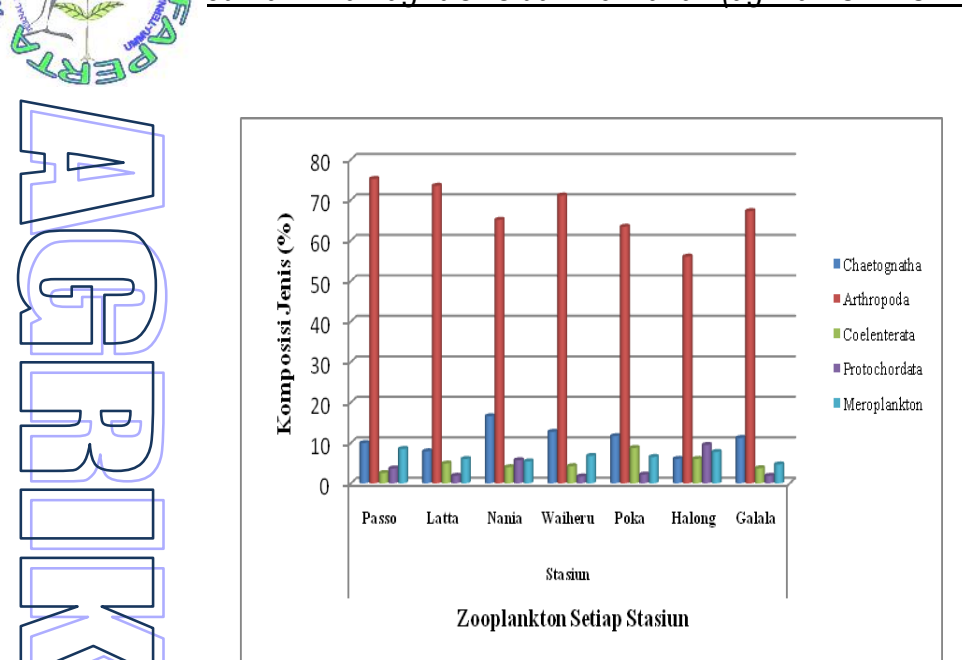

Gambar 5. Komposisi Jenis Zooplankton Bulan Juni (Sumber : Data Primer 2012)

Tabel 1. Holoplankton yang Ditemukan

\begin{tabular}{|c|c|c|c|c|c|c|c|}
\hline Phylum & Sub Phylum & Kelas & Sub Kelas & Ordo & Famili & Genus & Jenis \\
\hline \multirow{2}{*}{ CHAETOGNATHA } & & \multirow{2}{*}{ Sagittidea } & & \multirow{2}{*}{ Aphragmophora } & Krohniritidae & Krohnitta & Krohisitta sp \\
\hline & & & & & Saģtidide & Sagitta & Sagitta $s p$ \\
\hline \multirow{24}{*}{ ARTHROPODA } & \multirow{24}{*}{ Constaces } & Branchiopoda & Phyllopoda & Cladocera & Sididae & Perilia & Penilia sp \\
\hline & & \multirow{2}{*}{ Ostracoda } & \multirow{2}{*}{ Myodocopa } & & & Euchonchaecia & Euchonchaecia sp \\
\hline & & & & Myodocopidats & Cyprifididae & Pyrocypris & Pyrocypris sp \\
\hline & & \multirow{16}{*}{ Hexanauyplia } & \multirow{16}{*}{ Copeponds } & \multirow{10}{*}{ Calanoida } & Acartidae & Acartia & Acartia sp \\
\hline & & & & & Candacidare & Candacia & Candacia sp \\
\hline & & & & & Centropagidae & Centropages & Centropages sp \\
\hline & & & & & \multirow{3}{*}{ Eucalaridae } & Acrocalonus & Acrocalanus sp \\
\hline & & & & & & Eucalanus & Eucalamus sp \\
\hline & & & & & & Rhincalanus & Rhincalanus sp \\
\hline & & & & & \multirow{3}{*}{ Pontellidae } & Labidocera & Labidocera sp \\
\hline & & & & & & Ponitlla & Pontella sp \\
\hline & & & & & & Pontillopsis & Pontellopsis sp \\
\hline & & & & & Temoridae & Temora & Temora sp \\
\hline & & & & \multirow{4}{*}{ Cyclopoida } & Othoridae & Othoma & Oithona sp \\
\hline & & & & & Oncaeidae & Oncaea & Oncaea sp \\
\hline & & & & & Sapphirnidae & Sapphirina & Sapphirina sp \\
\hline & & & & & \begin{tabular}{|l|} 
Corycaedidae \\
\end{tabular} & Corycaeus & Concaeus sp \\
\hline & & & & \multirow{2}{*}{ Harapacticioda } & Nacrostetlibia & Macrostella & Macrosetella sp \\
\hline & & & & & Chytemnestadize & Clytemnestra & Clytemnestra sp \\
\hline & & \multirow{5}{*}{ Malacostraca } & \multirow{5}{*}{ Eumalacostraca } & Amplipoda & Hyperidze & Hyperia & Hiperia sp \\
\hline & & & & \multirow{2}{*}{ Decapoda } & Sergestidae & Acteres & Actes sp \\
\hline & & & & & Lucifenidae & Lucifer & Lucifer sp \\
\hline & & & & Euphasisicea & Euphausidide & Psendeuphausia & Psendery hausia sp \\
\hline & & & & Mysidacea & Mysidae & Mysis & Mysis sp \\
\hline \multirow{2}{*}{ COELENTERATA } & & \multirow{2}{*}{ Hydrozoa } & & Hydroida & & Medisa & Medisa sp \\
\hline & & & Hitrocidotima & Siphonopphora & Physalidae & Physalia & Physalia sp \\
\hline \multirow{2}{*}{ PROTOCHORDATA } & & \multirow{2}{*}{ Urochardata } & & Appendicularia & & Lanacea & Lanacea sp \\
\hline & & & & Thatiaces & & Thaliacea & Thaliacea sp \\
\hline
\end{tabular}

Sumber: Data Primer 2012

Selanjutnya holoplankton yang tergolong dalam 4 phylum terdiri atas 7 kelas yaitu Sagittoidea (2 jenis), Branchiopoda (1 jenis), Ostracoda (2 jenis), Hexanauplia (16 jenis), Malacostraca (5 jenis), Hydrozoa (2 jenis) dan Urochordata ( 2 jenis). Terdapat jenis yang tidak ditemukan pada bulan Juni tetapi ditemukan pada bulan Mei yaitu Mysis sp (Malacostraca) sedangkan jenis Acartia sp (Calanoida), Pontella sp (Calanoida) dan Clytemnestra sp (Harpactioida) ditemukan pada bulan Juni namun tidak ditemukan pada bulan Mei. Kelas
Hexanauplia memiliki jumlah jenis terbanyak karena terdiri dari sub kelas Copepoda dengan tiga ordo yaitu Calanoida (10 jenis), Cyclopida (4 jenis) dan Harpacticoida (2 jenis). Jenis zooplankton yang ditemukan dapat dilihat pada tabel 1 dan 2 .

Tabel 2. Meroplankton yang Ditemukan

\begin{tabular}{|c|c|}
\hline No. Urut & Meroplankton \\
\hline 1 & Larva Annelida \\
\hline 2 & Larva Bipinnaria \\
\hline 3 & Larva Bivalvia \\
\hline 4 & Larva Calanasid \\
\hline 5 & Larva Cirripedia \\
\hline 6 & Larva Gastropoda \\
\hline 7 & Larva Ikan \\
\hline 8 & Larva Leptochela \\
\hline 9 & Larva Palamonidae \\
\hline 10 & Larva Peneidae \\
\hline 11 & Larva Phoronis \\
\hline 12 & Larva (Zoea) \\
\hline 13 & Brachyura \\
\hline Sumber : Data Primer 2012
\end{tabular}

Komposisi zooplankton pada bulan Mei

dan Juni dapat dilihat pada tabel $3,4,5,6$ dan gambar 6,7 di bawah ini.

Tabel 3. Komposisi Zooplankton Bulan Mei

\begin{tabular}{|c|c|c|c|c|c|c|c|}
\hline \multirow{2}{*}{ Phylum } & \multicolumn{7}{|c|}{ Stasiun } \\
\cline { 2 - 8 } & Pass0 & Latta & Nania & Waiheru & Poka & Halong & Galala \\
\hline Holoplankton: & & & & & & & \\
\hline Chaetognatha & 10,6 & 5,53 & 7,62 & 14,63 & 20,47 & 9,02 & 9,38 \\
\hline Arthropoda & 46,87 & 56,85 & 53,38 & 50,14 & 46,77 & 69,4 & 61,24 \\
\hline Coelenterata & 5,29 & 10,66 & 8,43 & 3,76 & 10,23 & 10,83 & 4,96 \\
\hline Protochordata & 25,71 & 19,36 & 22,88 & 20,07 & 10,73 & 6,02 & 8,82 \\
\hline Meroplankton & 11,41 & 7,49 & 6,82 & 11,25 & 11,86 & 6,61 & 13,78 \\
\hline
\end{tabular}

Sumber: Data Primer, 2012

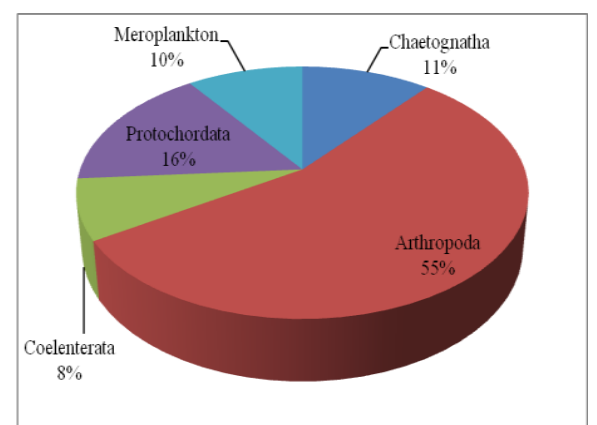

Gambar 6. Rata-rata Komposisi Zooplankton Bulan Mei (Sumber : Data Primer 2012) 

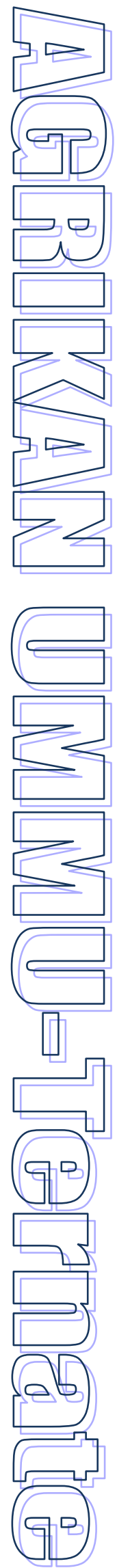

Berdasarkan tabel dan gambar di atas, terlihat bahwa pada bulan Mei phylum Arthropoda mendominasi daerah penelitian dengan komposisi rata-rata sebesar $55 \%$ dan tertinggi pada stasiun Halong sebesar 69,4\%. Besar komposisi Arthropoda disebabkan oleh tingginya komposisi jenis sub kelas Copepoda. Jenis dari Copepoda yang mendominasi adalah Acrocalanus sp, Eucalanus sp, Rhincalanus sp, Oithona sp dan Corycaeus sp. Sedangkan phylum yang memilki komposisi rata-rata terendah yaitu Coelenterata sebesar $8 \%$ yang terdiri dari genus Medusa sp dan Physalia sp.

Komposisi jenis pada bulan Mei terdapat 37 jenis yang ditemukan, dimana terdapat 6 jenis zooplankton yang tidak ditemukan pada bulan Mei namun hanya ada pada bulan Juni yaitu Acartia sp, Pontella sp, Clytemnestra sp, Larva Calanasid, Larva Cirripedia dan Larva ikan, sebaliknya pada bulan Juni ditemukan sebanyak 40 jenis dan 3 jenis tidak ditemukan pada bulan Juni tetapi ditemukan pada bulan Mei yaitu Mysis sp, larva Peneidae dan larva (Zoea) Brachyura.

Tabel 4. Komposisi Jenis Zooplankton Bulan Mei

\begin{tabular}{|c|c|c|c|c|c|c|c|c|c|}
\hline \multirow{2}{*}{ ZOOPLANKTON } & \multirow{2}{*}{ Jenis } & \multicolumn{7}{|c|}{ Stasiun } & \multirow{2}{*}{ Jumlah } \\
\hline & & Passo & Latta & Nania & Waiheru & Poka & Halong & Galala & \\
\hline \multirow{27}{*}{ HOLOPLANKTON } & Krobritta sp & 1.63 & 1.58 & 0.8 & 5.43 & 2.43 & 1.8 & 22 & 15.87 \\
\hline & Sagitta sp & 8.97 & 3.95 & 6.82 & 9.2 & 18.04 & 7.22 & 7.18 & 61.38 \\
\hline & Penilia sp & 15.51 & 10.67 & 11.64 & 8.78 & 8.78 & 13.25 & 8.28 & 76.91 \\
\hline & Euchonchaecia sp & 0.4 & 3.95 & 1.6 & 7.11 & 1.46 & 0.6 & 0.55 & 15.67 \\
\hline & Pyrocypris sp & 0 & 0.39 & 0 & 0 & 0 & 0.6 & 1.1 & 2.09 \\
\hline & Candacia sp & 0.4 & 0 & 0 & 0 & 0.48 & 1.8 & 0 & 2.68 \\
\hline & Centropages sp & 1.63 & 0.39 & 0 & 0.83 & 0.48 & 0.6 & 1.1 & 5.03 \\
\hline & Acrocalanus sp & 7.34 & 10.67 & 18.47 & 5.43 & 6.34 & 4.21 & 12.7 & 65.16 \\
\hline & Eucalanus sp & 0 & 11.06 & 10.44 & 1255 & 16.58 & 11.44 & 7.73 & 69.8 \\
\hline & Rhincalanus sp & 2.04 & 4.34 & 1.2 & 1.25 & 0.48 & 9.63 & 9.94 & 28.88 \\
\hline & Labidocera sp & 0 & 0 & 0 & 0 & 0 & 1.8 & 2.2 & 4 \\
\hline & Pontellopsis sp & 0.4 & 0 & 0 & 0 & 0.48 & 0.6 & 1.1 & 2.58 \\
\hline & Temora sp & 0 & 0.39 & 0.4 & 1.25 & 0.97 & 0 & 0.55 & 3.56 \\
\hline & Oithona sp & 7.75 & 3.55 & 5.62 & 4.6 & 1.95 & 1.80 & 4.41 & 27.88 \\
\hline & Onceea sp & 0.81 & 0.39 & 0 & 0 & 0 & 0 & 0.55 & 1.75 \\
\hline & Sapphirina $\mathrm{sp}$ & 0.81 & 0.39 & 0 & 0 & 0 & 0.6 & 0 & 1.8 \\
\hline & Corycaeus sp & 1.63 & 2.76 & 0.4 & 2.51 & 1.95 & 3.01 & 2.2 & 14.46 \\
\hline & Macrosetella sp & 0 & 0 & 0 & 0 & 0 & 0.6 & 0 & 0.6 \\
\hline & Hyperia sp & 0 & 0 & 0.4 & 0 & 0 & 0 & 0 & 0.4 \\
\hline & Actes sp & 0.81 & 1.58 & 0.8 & 2.09 & 0 & 3.01 & 1,65 & 8.29 \\
\hline & Lucifer sp & 7.34 & 6.32 & 241 & 3.33 & 6.82 & 15.25 & 8.28 & 49.75 \\
\hline & Psendeuphausia sp & 0 & 0 & 0 & 0.41 & 0 & 0.6 & 0 & 1.01 \\
\hline & Mysis sp & 0 & 0 & 0 & 0 & 0 & 0 & 0.55 & 0.55 \\
\hline & Medisa sp & 2.44 & 6.71 & 5.22 & 1.25 & 6.82 & 6.02 & 1.65 & 30.11 \\
\hline & Physalia sp & 2.85 & 3.95 & 3.21 & 2.51 & 3.41 & 4.81 & 3.31 & 24.05 \\
\hline & Lavracea sp & 4.08 & 1.18 & 6.82 & 2.92 & 1.95 & 0 & 22 & 19.15 \\
\hline & Thaliacea sp & 21.63 & 18.18 & 16.06 & 17.15 & 8.78 & 6.02 & 6.62 & 94.44 \\
\hline \multirow{10}{*}{ IIEROPLANKTON } & Larva Annebida & 0.4 & 0.39 & 0 & 0.83 & 1.46 & 1.2 & 2.76 & 7.04 \\
\hline & Larva Bipinnaria & 8.57 & 5.53 & 5.22 & 7.94 & 7.51 & 3.61 & 6.07 & 44.45 \\
\hline & Larva Bivalia & 0 & 0 & 0 & 0.41 & 0.48 & 0.6 & 1.1 & 2.59 \\
\hline & Larva Gastropoda & 0 & 0.79 & 0 & 0 & 0.48 & 0 & 0.55 & 1.82 \\
\hline & Larva Leptochela & 0 & 0 & 0 & 0 & 0.48 & 0 & 1.65 & 2.13 \\
\hline & Larva Palamonidae & 0.4 & 0 & 0 & 0.41 & 0.97 & 0 & 0.55 & 2.33 \\
\hline & Larva Peneidae & 0 & 0.39 & 0.4 & 0 & 0 & 0 & 0 & 0.79 \\
\hline & Larva Phoronis & 0 & 0 & 0 & 0 & 0 & 0.6 & 0 & 0.6 \\
\hline & Larva (Zoea) Brachyura & 0 & 0.39 & 0.4 & 0.41 & 0.48 & 0 & 1.1 & 2.78 \\
\hline & Tehr van & 204 & 0 & 0.8 & 1.25 & 0 & 0.6 & 0 & 4.69 \\
\hline
\end{tabular}

Sumber: Data Primer, 2012
Tabel 5. Komposisi Zooplankton Bulan Juni

\begin{tabular}{|c|c|c|c|c|c|c|c|}
\hline \multirow{2}{*}{ Phylum } & \multicolumn{7}{|c|}{ Stasiun } \\
\cline { 2 - 9 } & Passo & Latta & Nania & Waiheru & Poka & Halong & Galala \\
\hline Holoplankton : & & & & & & & \\
\hline Chaetognatha & 9.94 & 7.92 & 16.56 & 12.71 & 11.66 & 6.03 & 11.2 \\
\hline Arthropoda & 75.18 & 73.49 & 65.09 & 71.08 & 63.38 & 55.99 & 67.23 \\
\hline Coelenterata & 2.55 & 4.9 & 3.99 & 4.23 & 8.74 & 6.03 & 3.73 \\
\hline Protochordata & 3.68 & 1.88 & 5.71 & 1.68 & 2.18 & 9.47 & 1.86 \\
\hline Meroplankton & 8.49 & 6.01 & 5.41 & 6.76 & 6.51 & 7.75 & 4.67 \\
\hline
\end{tabular}

Sumber: Data Primer, 2012

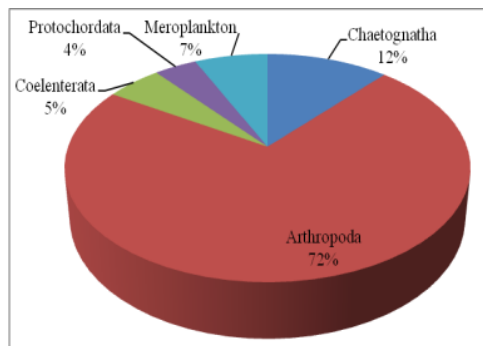

Gambar 7. Rata-rata Komposisi Zooplankton Bulan Juni (Sumber : Data Primer 2012)

Tabel 6. Komposisi Jenis Zooplankton Bulan Juni

\begin{tabular}{|c|c|c|c|c|c|c|c|c|c|}
\hline \multirow{2}{*}{ ZOOPLANKTON } & \multirow{2}{*}{ Jenis } & \multicolumn{7}{|c|}{ Stasiun } & \multirow{2}{*}{ Jumlah } \\
\hline & & Passo & Latta & Nania & Waiheru & Poka & Halong & Galala & \\
\hline \multirow{29}{*}{ HOLOPLANKTION } & Krohnitta $\mathrm{sp}$ & 0.85 & 2.26 & 2.28 & 0 & 3.64 & 1.72 & 1.86 & 12.61 \\
\hline & Sagitta sp & 9.09 & 5.66 & 14.28 & 12.71 & 8.02 & 4.31 & 9.34 & 63.41 \\
\hline & Penilia sp & 3.4 & 6.03 & 4.57 & 0.84 & 0.72 & 4.31 & 1.86 & 21.73 \\
\hline & Euchonchaecia sp & 4.82 & 3.77 & 2.28 & 9.32 & 1.45 & 0 & 0.93 & 22.57 \\
\hline & Pyrocypris sp & 1.7 & 1.13 & 0 & 3.38 & 0.72 & 0 & 0 & 6.93 \\
\hline & Acortia sp & 0.85 & 1.5 & 1.71 & 1.69 & 5.1 & 1.72 & 5.6 & 18.17 \\
\hline & Condacia sp & 1.13 & 1.5 & 0 & 0.84 & 0 & 1.72 & 0 & 5.19 \\
\hline & Centropages sp & 0 & 0.37 & 1.14 & 0.84 & 0 & 2.58 & 0 & 4.93 \\
\hline & Acrocalanus sp & 11.07 & 18.11 & 12 & 16.1 & 8.75 & 16.37 & 14.95 & 97.35 \\
\hline & Eucalanus sp & 28.97 & 10.94 & 12.57 & 17.79 & 19.7 & 13.79 & 16.82 & 120.58 \\
\hline & Rhincalanus sp & 3.4 & 3.77 & 5.71 & 0.84 & 0.72 & 0 & 1.86 & 16.3 \\
\hline & Labidocera sp & 3.69 & 6.41 & 3.42 & 8.47 & 10.94 & 1.72 & 5.6 & 40.25 \\
\hline & Pontella sp & 0.28 & 0 & 0 & 0 & 0 & 0 & 0 & 0.28 \\
\hline & Pontellopsis sp & 2.27 & 1.13 & 3.42 & 0.84 & 2.18 & 0.86 & 0 & 10.7 \\
\hline & Temora sp & 1.7 & 0.75 & 1.14 & 0 & 0 & 0 & 0 & 3.59 \\
\hline & Othona sp & 3.69 & 7.16 & 4 & 3.38 & 6.56 & 0 & 3.73 & 28.52 \\
\hline & Oncaea sp & 0.56 & 0.37 & 0 & 0 & 0 & 0.86 & 0.93 & 2.72 \\
\hline & Sapphirina sp & 0.85 & 0.37 & 0 & 0.84 & 0 & 0 & 0 & 2.06 \\
\hline & Corycaeus sp & 4.26 & 6.41 & 5.14 & 3.38 & 3.64 & 6.03 & 6.54 & 35.4 \\
\hline & Macrosetella sp & 0 & 0 & 0 & 0 & 1.45 & 0 & 0 & 1.45 \\
\hline & Clytemnestra sp & 0 & 0 & 0.57 & 0 & 0 & 0 & 0 & 0.57 \\
\hline & Hyperia sp & 0 & 0 & 0 & 0.84 & 0 & 0 & 0 & 0.84 \\
\hline & Acctes sp & 0.85 & 3.77 & 7.42 & 1.69 & 1.45 & 5.17 & 8.41 & 28.76 \\
\hline & Lucifer sp & 1.69 & 0 & 0 & 0 & 0 & 0 & 0 & 1.69 \\
\hline & $P_{\text {sendeuphausin } \mathrm{sp}}$ & 0 & 0 & 0 & 0 & 0 & 0.86 & 0 & 0.86 \\
\hline & Meausa sp & 2.55 & 2.26 & 3.42 & 2.54 & 7.29 & 5.17 & 0.93 & 24.16 \\
\hline & Physalia sp & 0 & 2.64 & 0.57 & 1.69 & 1.45 & 0.86 & 2.8 & 10.01 \\
\hline & Larvacea sp & 1.7 & 1.13 & 1.14 & 0.84 & 2.18 & 1.72 & 0.93 & 9.64 \\
\hline & Thaliacea sp & 1.98 & 0.75 & 4.57 & 0.84 & 0 & 7.75 & 0.93 & 16.82 \\
\hline \multirow{11}{*}{ MEROPLANKTON } & Larva Annelida & 3.4 & 2.64 & 0 & 3.38 & 1.45 & 0.86 & 0 & 11.73 \\
\hline & Larra Bipimaria & 1.98 & 1.13 & 1.14 & 2.54 & 1.45 & 1.72 & 4.67 & 14.63 \\
\hline & Larva Bivalvia & 1.42 & 0.75 & 1.71 & 0 & 0.72 & 4.31 & 0 & 8.91 \\
\hline & Larva Calanasid & 0 & 0 & 0 & 0 & 1.45 & 0 & 0 & 1.45 \\
\hline & Larva Ciminecủa & 0 & 0 & 0.57 & 0 & 0 & 0.86 & 0 & 1.43 \\
\hline & Larva Gastropoda & 0.85 & 0.75 & 0.57 & 0 & 0 & 0 & 0 & 2.17 \\
\hline & Larva Ikan & 0.28 & 0 & 0 & 0 & 0 & 0 & 0 & 0.28 \\
\hline & Lavya Leptochela & 0.56 & 0 & 0 & 0.84 & 0.72 & 0 & 0 & 2.12 \\
\hline & Larva Palamonidae & 0 & 0.37 & 1.42 & 0 & 0 & 0 & 0 & 1.79 \\
\hline & Larva Phorotonis & 0 & 0.37 & 0 & 0 & 0 & 0 & 0 & 0.37 \\
\hline & Telur kan & 0 & 0 & 0 & 0 & 0.72 & 0 & 0 & 0.72 \\
\hline
\end{tabular}

Sumber: Data Primer, 2012

Dari tabel dan gambar di atas, ternyata komposisi zooplankton tertinggi pada bulan Juni juga phylum Arthropoda dengan 

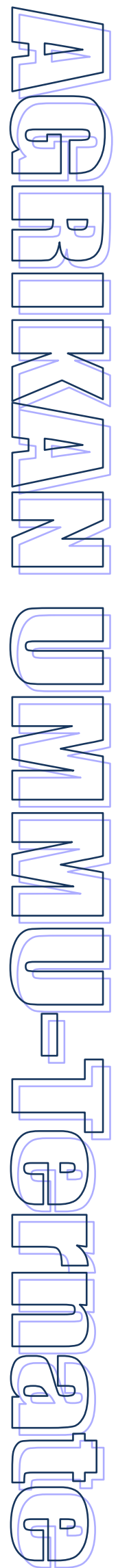

komposisi rata-rata sebesar $72 \%$ dan tertinggi pada stasiun Passo sebesar $75,18 \%$. Komposisi rata-rata terendah pada bulan Juni yaitu phylum Protochordata sebesar $4 \%$.

Ternyata pada 2 bulan penelitian ditemukan sub phylum Crustacea lebih tinggi komposisinya. Hal ini diperkuat oleh pernyataan Wickstead (1965) bahwa Crustacea memiliki adaptasi lebih baik dengan perairan, dapat hidup dan berkembang biak hanya pada lingkungan yang cocok. Crustacea yang ditemukan di lokasi penelitian didominasi oleh sub kelas Copepoda.

Komposisi zooplankton mengalami perubahan pada setiap bulan pengamatan. Komposisi Arthropoda dan Chetognatha lebih tinggi pada bulan Juni, sedangkan Protochordata, Colenterata dan Meroplankton memiliki komposisi yang lebih tinggi pada bulan Mei. Berfluktuasinya komposisi zooplankton yang ditemukan di lokasi penelitian, ternyata juga ditemukan oleh Pelasula dan Mudjiono (2007) dalam Karuwal (2015) di Teluk Ambon pada bulan Februari hingga Agustus 2007, zooplankton didominasi oleh kelompok Copepoda jenis Calanoida sp dan Cyclopoida sp sebesar $18,20-93,77 \%$. Selanjutnya penelitian Mulyadi dan Radjab (2009) dalam Karuwal (2015) juga mendapatkan bahwa zooplankton yang predominan di teluk Ambon adalah jenis Copepoda, Meroplankton, Lucifera, Thaliacea dan Chaetognatha.

\subsection{Kepadatan Zooplankton}

Kepadatan zooplankton pada bulan Mei tertinggi pada stasiun Latta dengan nilai $31.878 \mathrm{ind} / \mathrm{m}^{3}$ dan terendah pada stasiun Halong dengan nilai kepadatan sebesar $20.916 \mathrm{ind} / \mathrm{m}^{3}$. Tingginya kepadatan zooplankton di stasiun Latta diasumsikan karena dekat dengan pemukiman penduduk sehingga adanya pembuangan limbah rumah tangga berupa bahan organik yang dimanfaatkan oleh detritus. Hal ini diperkuat oleh pernyataan Pennak (1978) bahwa makanan zooplankton yang utama adalah fitoplankton, namun pada kondisi tertentu zooplankton dapat pula memanfaatkan bakteri atau detritus yang pada akhirnya memicu kepadatan zooplankton yang tinggi.
Tabel 7. Kepadatan Zooplankton Bulan Mei (ind $/ \mathrm{m}^{3}$ ).

\begin{tabular}{c|c|c|c|c|c|c|c|}
\multirow{2}{*}{ Phylum } & \multicolumn{7}{|c|}{ Stasiun } \\
\cline { 2 - 8 } & Passo & Latta & Nania & Waiheru & Poka & Halong & Galala \\
\hline CHAETOGNATHA & 3276 & 1764 & 2394 & 4410 & 5292 & 1890 & 2142 \\
\hline ARTHROPODA & 14490 & 18144 & 17388 & 15120 & 12096 & 14112 & 14238 \\
\hline COELENTERATA & 1638 & 3402 & 2646 & 1134 & 2646 & 2268 & 1134 \\
\hline PROTOCHORDATA & 7938 & 6174 & 7182 & 6048 & 2772 & 1260 & 2016 \\
\hline MEROPLANKTON & 3528 & 2394 & 2142 & 3402 & 3024 & 1386 & 3150 \\
\hline Jumlah & 30870 & 31878 & 31752 & 30114 & 25830 & 20916 & 22680 \\
\hline
\end{tabular}

Sumber: Data Primer 2012

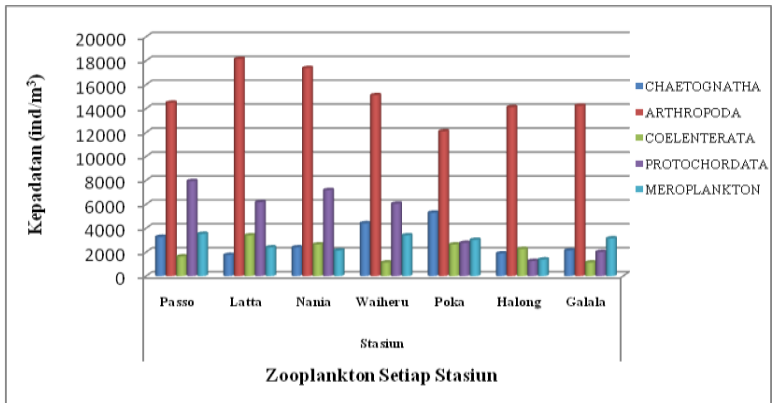

Gambar 8. Grafik Kepadatan Zooplankton Bulan Mei. (Sumber : Data Primer 2012)

Tabel 8. Kepadatan Jenis Zooplankton Bulan Mei ind $/ \mathrm{m}^{3}$ )

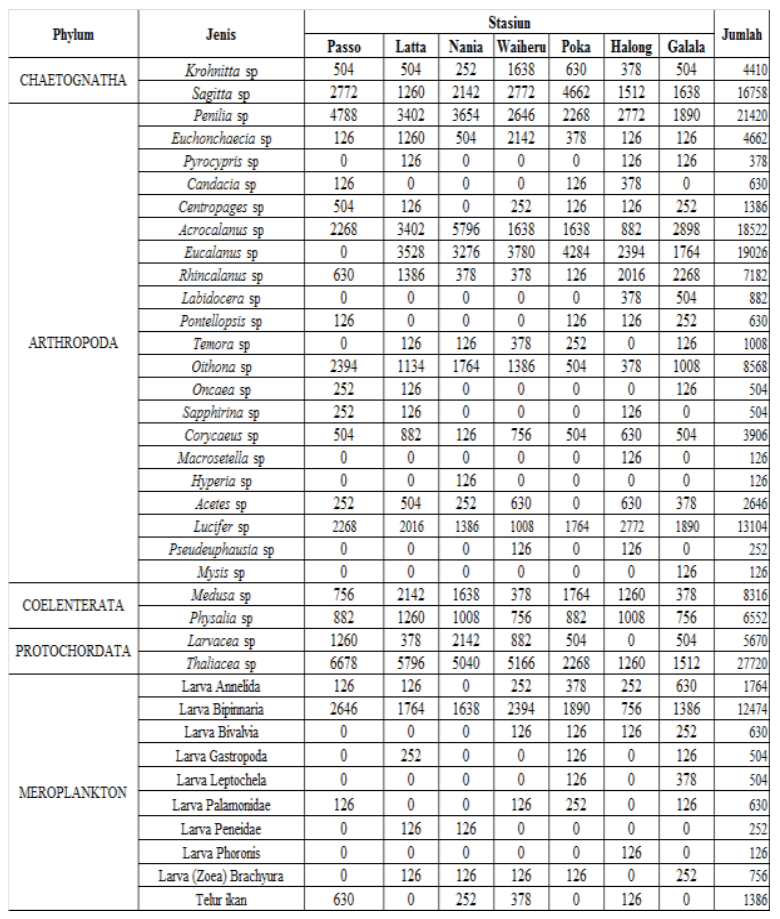

Sumber: Data Primer 2012

Kepadatan zooplankton bulan Juni, tertinggi juga ditemukan pada stasiun Latta sebesar $33.516 \mathrm{ind} / \mathrm{m}^{3}$ dan terendah pada stasiun Halong sebesar $14.364 \mathrm{ind} / \mathrm{m}^{3}$. Rendahnya kepadatan zooplankton pada kedua bulan di stasiun Halong, hal ini diasumsikan posisi 

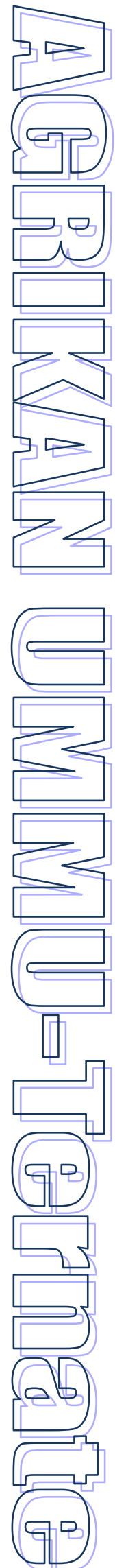

stasiun Halong yang dekat dengan pelabuhan dipengaruhi oleh aktivitas pembuangan bilasan air kapal serta penumpahan minyak menyebabkan daerah tersebut terganggu kualitas perairannya sehingga menghambat pertumbuhan zooplankton. Sebagaimana pernyataan Basit $d k k$ (2008) bahwa tumpahan minyak serta aktifitas transportasi mempengaruhi kualitas perairan di Teluk Ambon.

Tabel 9. Kepadatan Zooplankton Bulan Juni (ind $/ \mathrm{m}^{3}$ )

\begin{tabular}{c|c|c|c|c|c|c|c|}
\multirow{2}{*}{ Phylum } & \multicolumn{7}{|c|}{ Stasiun } \\
\cline { 2 - 8 } & Passo & Latta & Nania & Waiheru & Poka & Halong & Galala \\
\hline CHAETOGNATHA & 4410 & 2646 & 3654 & 1890 & 2016 & 882 & 1512 \\
\hline ARTHROPODA & 33395 & 26586 & 15120 & 11340 & 12222 & 10080 & 11718 \\
\hline COELENTERATA & 1134 & 1638 & 882 & 630 & 1512 & 882 & 504 \\
\hline PROTOCHORDATA & 1638 & 630 & 1260 & 252 & 378 & 1386 & 252 \\
\hline NEROPLANKTON & 3780 & 2016 & 1134 & 1008 & 1134 & 1134 & 630 \\
\hline Jumlah & 44357 & 33516 & 22050 & 15120 & 17262 & 14364 & 14616 \\
\hline
\end{tabular}

Sumber: Data Primer 2012

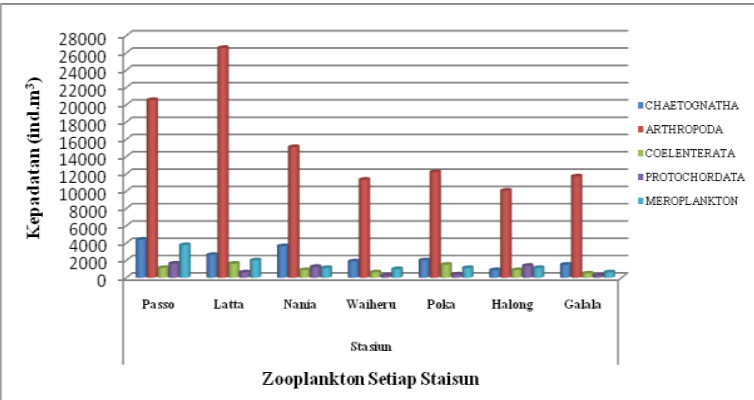

Gambar 9. Grafik Kepadatan Zooplankton Bulan Juni. (Sumber : Data Primer 2012)

Kepadatan zooplankton kedua bulan pengamatan didominasi oleh phylum Arthropoda sub kelas Copepoda. Hal yang sama juga ditemukan oleh Karuwal (2015) di Teluk Ambon Dalam serta oleh Mulyadi dan Radjab (2015) di Morella Maluku Tengah. Tingginya Copepoda diperkuat oleh pernyatan Kennish (1990) dan Nybakken (1988) bahwa kelompok holoplankton yang dominan di estuari adalah Crustasea dimana Copepoda merupakan hewan herbivora yang umumnya mendominasi perairan, kemudian Cladosera, Ostracoda, Sergestidae, Hyperia, Chaetognatha, Urochordata, Siphonophora, Medusa, dan Meroplankton (larva organisme laut).
Tabel 10. Kepadatan Jenis Zooplankton Bulan Mei (ind $/ \mathrm{m}^{3}$ )

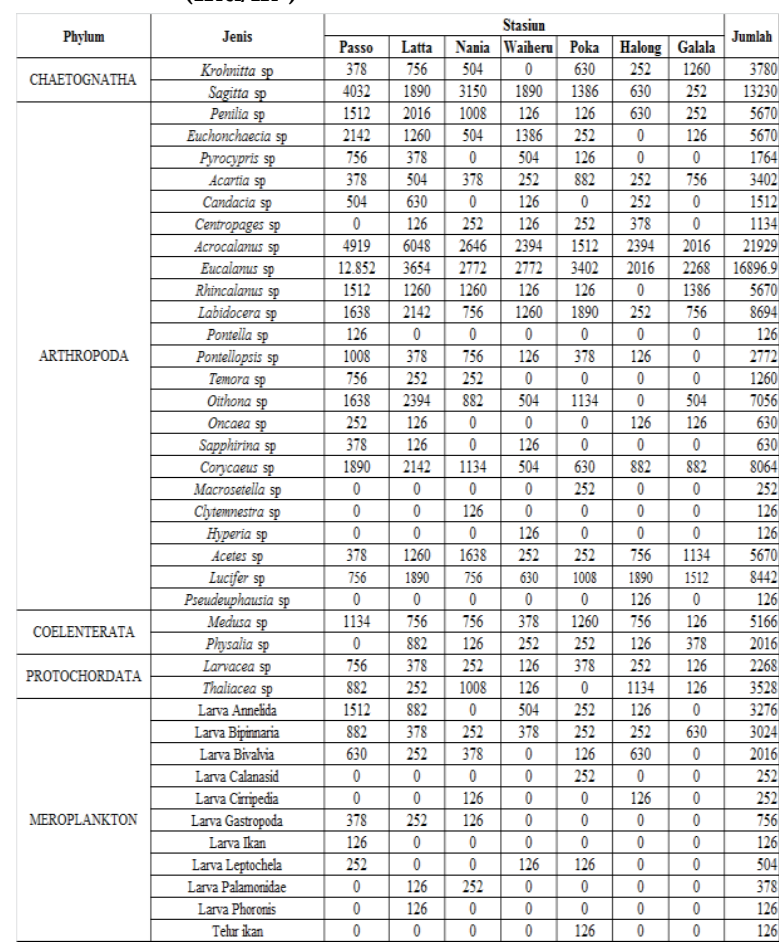

Sumber: Data Primer 2012

Selanjutnya Nontji (2008) juga mengemukakan bahwa Copepedo berhubungan dengan kelimpahan fitoplankton dan memegang peranan penting dalam rantai makanan serta dimanfaatkan oleh konsumen di atasnya. Menurut Mulyadi dan Radjab (2015) tingginya persentase kelimpahan Copepoda diduga terkait dengan kemampuannya dalam beradaptasi terhadap kondisi oseanografi di daerah pesisir yang sangat dinamis (temperatur dan salinitas) bila dibandingkan dengan kelompok zooplankton yang lain. Kondisi ini tentu juga didukung dengan ketersediaan fitoplankton yang menjadi pakan alaminya. Hal ini sejalan dengan pernyataan sejumlah ahli (Baars et al, 1990; Arinardi, 1996; Rezai et al, 2004 dan Eloire et al, 2010 dalam Mulyadi dan Radjab, 2015) yang menjelaskan bahwa Copepoda melimpah di perairan pesisir dengan nilai lebih dari $50 \%$ dari total zooplankton.

Tinginya kepadatan zooplankton bulan Mei dari bulan Juni, hal diasumsikan karena juga ditemukan kepadatan fitoplankton lebih tinggi pada bulan Mei sebesar 140,3 x 10 sel/liter jika dibandingkan dengan bulan Juni sebesar 25,1 x 105 sel/liter (LIPI Ambon, 2012) Kepadataan fitoplankton akan mempengaruhi pertumbuhan zooplankton, sebagaimana 


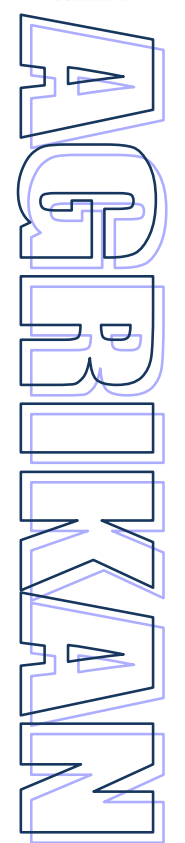

pernyataan Karuwal (2015) bahwa melimpahnya zooplankton pada waktu dan kedalaman diduga berhubungan dengan melimpahnya komunitas fitoplankton pada perairan. Selanjutnya Mulyadi dan Radjab (2015) juga mengemukakan bahwa tingginya kelimpahan zooplankton Copepoda didukung dengan ketersediaan fitoplankton yang menjadi pakan alaminya.

\section{PENUTUP}

\subsection{Kesimpulan}
Dari hasil
pembahasan
dapat

\subsection{Saran}

disimpulkan bahwa:

1. Komposisi jenis yang ditemukan pada bulan Mei sebanyak 27 jenis holoplankton dan meroplankton sebanyak 10 kelompok sedangkan bulan Juni ditemukan

holoplankton sebanyak 29 jenis dan meroplankton sebanyak 11 kelompok

2. Zooplankton yang ditemukan terdiri dari holoplankton sebanyak 4 phylum yaitu Chaetognatha, Arthropoda, Coelenterata dan Protochordata sedangkan meroplakton terdiri dari Molusca, Echinodermata, Annelida dan Larva Ikan.

3. Kepadatan zooplankton tertinggi pada stasiun Latta dan terendah pada stasiun Halong.

Diharapkan adanya penelitian lanjutan mengenai struktur komunitas zooplankton dalam hubungannya dengan faktor lingkungan serta interval waktu dan kedalaman yang berbeda di perairan Teluk Ambon Dalam.

\section{DAFTAR PUSTAKA}

Arinardi, O. H. 1976. Plankton; Fitoplankton dan Zooplankton. Jakarta: PT Gramedia Pustaka Utama.

Basit, A., Mudjiono dan M.R.Putri. 2008. Monitoring Oseanigrafi Fisis di Teluk Ambon

Fachrul, F. M. 2006. Metode Sampling Bioekologi, Bumi Aksara, Jakarta.

Karuwal,J.W.Ch. 2015. Hubungan Parameter Fisik Perairan Dengan Struktur Menegak Komunitas Plankton Di Teluk Ambon Dalam. Jurnal Agroforestri X Nomor 1 Maret 2015 hal 73-84

Kaswadji, R. 2001. Keterkaitan Ekosistem Di Dalam Wilayah Pesisir. Sebagian bahan kuliah SPL.727 (Analisis Ekosistem Pesisir dan Laut). Fakultas Perikanan dan Kelautan IPB. Bogor, Indonesia.

Kennish,M.J. 1990. Ecology of Estuaries Vol II : Biological Aspects. CRC Press Inc, Boca Raton. USA. 391p

LIPI Ambon. 2012. Hasil Monitoring Teluk Ambon Dalam.

Mulyadi,H.A dan A.W.Radjab. 2015. Dinamika Spasial Kelimpahan Zooplankton Pada Musim Timur Di Perairan Pesisir Morella, Maluku Tengah. Jurnal Ilmu dan Teknologi Kelautan Tropis, Vol. 7, No. 1, Hlm. 109-122, Juni 2015

Nontji, A. 1996. Status Kondisi Hidrologi, Sedimentasi dan Biologi Teluk Ambon Saat Ini (Prosiding Seminar dan Lokakarya Pengelolaan Teluk Ambon) Hal 1-6.

Nontji, A. 1987. Laut Nusantara. Penerbit Djambatan. Jakarta.

Nontji, A. 2008. Plankton Laut. Jakarta : LIPI Press.

Nybakken, J. W. 1988. Biologi Laut Suatu Pendekatan Ekologis. Jakarta:PT. Gramedia.

Pennak, R. W. 1978. Freshwater Invertebrates of United State. Second Edition. A. willey interscience publication John willey and Sons. Inc. New York.

Salili,Y., Pelasula, D.dan Sam Wouthuyzen. 2007. Monitoring Pencemaran Teluk Ambon.

Wickstead, J. H. 1965. An Introduction to The Tropical Plankton. Hutchinson and Co. Ltd. London. $160 \mathrm{p}$.

Yamaji, E. E. 1966. The Ilustration of Marine Plankton of Japan Hoikusha, Osaka, Japan, Third edition. 536 pp 